\title{
Burnout and psychiatric morbidity among doctors in the UK: a systematic literature review of prevalence and associated factors
}

\author{
Udemezue O. Imo ${ }^{1}$
}

BJPsych Bulletin (2017), 41, 197-204, doi: 10.1192/pb.bp.116.054247

${ }^{1}$ Royal Oldham Hospital, Oldham, UK Correspondence to Udemezue O. Imo (uimo@nhs.net)

First received 29 Mar 2016, final revision 25 Jun 2016, accepted 31 Aug 2016

(C) 2017 The Author. This is an openaccess article published by the Royal College of Psychiatrists and distributed under the terms of the Creative

Commons Attribution License (http:// creativecommons.org/licenses/by/ 4.0), which permits unrestricted use, distribution, and reproduction in any medium, provided the original work is properly cited.
Aims and method To systematically review the prevalence and associated factors of burnout and stress-related psychiatric disorders among UK doctors. An extensive search was conducted of PubMed, EBSCOhost and British medical journals for studies published over a 20-year span measuring the prevalence of psychiatric morbidity (using the General Health Questionnaire) and burnout (using the Maslach Burnout Inventory).

Results Prevalence of psychiatric morbidity ranged from 17 to $52 \%$. Burnout scores for emotional exhaustion ranged from 31 to $54.3 \%$, depersonalisation 17.4 to $44.5 \%$ and low personal accomplishment 6 to $39.6 \%$. General practitioners and consultants had the highest scores. Factors significantly associated with increase in the prevalence of burnout and psychiatric morbidity include low job satisfaction, overload, increased hours worked and neuroticism.

Clinical implications The results indicate a worryingly high rate of burnout and psychiatric morbidity among UK doctors, which could have a huge negative impact on healthcare provision in general. Factors at personal and organisational levels contribute to burnout and psychiatric morbidity, and so efforts made to counter these problems should target both levels.

Declaration of interest None.
Doctors have a legal duty broader than that of any other health professional and therefore a responsibility to contribute to the effective running of the organisation in which they work, and to its future direction. ${ }^{1}$ In an environment where their health and well-being is not prioritised doctors sometimes become ill, manifesting features of burnout and/or stress-related psychiatric disorders. Such psychiatric morbidity, or 'caseness', is detected using self-reported instruments such as the General Health Questionnaire (GHQ). ${ }^{2}$ Doctors also experience 'burnout', which is defined as a syndrome of exhaustion, cynicism and low professional efficacy. ${ }^{3}$ Maslach et $a l^{4}$ described burnout as a prolonged response to chronic emotional and interpersonal stressors on the job, and stated: 'What started out as important, meaningful, and challenging work becomes unpleasant, unfulfilling, and meaningless. Energy turns into exhaustion, involvement turns into cynicism, and efficacy turns into ineffectiveness'.

Increased prevalence of psychiatric morbidity and burnout has been established in studies from different parts of the world. A study of Italian physicians found an estimated prevalence of psychiatric morbidity to be $25 \%$, and prevalence of burnout on the emotional exhaustion scale of the Maslach Burnout Inventory (MBI) to be $38.7 \% .^{5}$
Other studies have reviewed the factors associated with the development and maintenance of psychiatric illness and burnout among doctors. A survey of Australian doctors found that having medico-legal issues, not taking a holiday in the previous year and working long hours were all significantly associated with psychiatric morbidity. ${ }^{6}$ Selfcriticism as a medical student was significantly correlated with psychological stress as a doctor in a cohort followed over 10 years by Firth-Cozens. ${ }^{7}$

Burnout among doctors can lead to self-reported suboptimal patient care $^{8}$ and to major medical errors. ${ }^{9}$ Psychiatric morbidity increases the likelihood of retirement thoughts and retirement preference. ${ }^{10}$ Behavioural responses to burnout established in the literature also include alcohol and drug misuse, physical withdrawal from co-workers, increased absenteeism, arriving for work late and leaving early, and employee turnover. ${ }^{11}$ An extreme reaction to stress can be suicide, even though the pathway to this is complex and multifactorial. A UK survey of suicides between 1979 and 1983 ranked the medical profession as 10th in the list of high-risk professions. ${ }^{12}$

Mental ill health can be found within every workplace in every country. In the UK the total cost to employers of mental health problems among their staff is estimated at 
nearly £26 billion each year: $£ 8.4$ billion from sickness absences and $£ 15.1$ billion from reduced productivity at work. $^{13}$ The National Institute for Health and Care Excellence (NICE) found that promoting the mental wellbeing of employees can yield economic benefits for the business or organisation, in terms of increased commitment and job satisfaction, staff retention, improved productivity and performance, and reduced staff absenteeism. ${ }^{14}$ For the National Health Service (NHS) to reap the benefits described by NICE, priority should be given to employee mental health. However, the constant structural changes to the NHS in England have created instability and lack of job security within the public health workforce. ${ }^{15}$ The Health and Social Care Act of 2012 has placed doctors at the centre of clinical commissioning groups in charge of shaping services and made them responsible for $£ 65$ billion of the $£ 95$ billion NHS commissioning budget. ${ }^{16}$ This imposes on doctors, especially general practitioners (GPs), a responsibility unlike any before ${ }^{17}$ one which their training has not prepared them for. The ability to cope with the challenges of working in the NHS and the possibility of stress and burnout were highlighted in the annual meeting of the British Medical Association in $2013,{ }^{18}$ and are the focus of this review.

Numerous research papers document burnout and stress-related psychiatric disorders in doctors worldwide, but none has presented the results in the form of a systematic review showing the prevalence and associated factors among UK doctors. The overall aim of this review was to redress this by assessing the prevalence of burnout and psychiatric morbidity among UK doctors working in different specialties, and to explore the associated identified factors. The objectives were to review the prevalence of the syndrome of burnout and psychiatric morbidity, to explore the nature of the relationship between burnout and psychiatric morbidity, and to identify other factors associated with the development and/or perpetuation of those conditions.

\section{Method}

\section{Search strategies}

The words 'burnout' and 'doctors' were put into the search field of the EBSCOhost website specifying the following databases: Academic Search Complete, CINAHL Plus, PsycINFO and PsycARTICLES. Limiters activated were: English language, human, apply related words, and a time limit of January 1993 to December 2013. A total of 562 articles resulted from this, reduced to 489 automatically after duplicates were removed; 28 articles were selected for further analysis, and out of these 9 remained based on the study inclusion and exclusion criteria. Using the same parameters but with the words 'psychiatric morbidity' AND 'doctors', a total of 97 articles were generated, reduced to 77 after the removal of duplicates, and from these only 1 was selected as new and appropriate. Again using the same parameters but with the words 'stress' AND 'doctors' NOT 'nurses', 3560 articles came up, reduced to 2259 after duplicates were removed; 23 new articles were reviewed in greater detail, and from these 5 new and appropriate articles were selected.

An advanced search on PubMed with the words 'doctors' OR 'physicians' AND 'stress', with a time limit of 1 January 1980 to 15 December 2013 and other limits (human, English language, clinical trial, journal article, reviews, lectures) generated 5973 articles. After careful analysis of the abstracts 28 new articles were identified for more detailed review, and from these 10 were selected as new and appropriate.

Two searches within the group of British medical journals with the phrases 'burnout and doctors' and 'doctors and stress' with the time limit of January 1993 to December 2013 yielded two new and appropriate papers.

A review of the reference lists of already-identified papers yielded three relevant papers.

Altogether, this extensive search yielded 30 relevant papers which were included in the units of analysis for this review (Fig. 1).

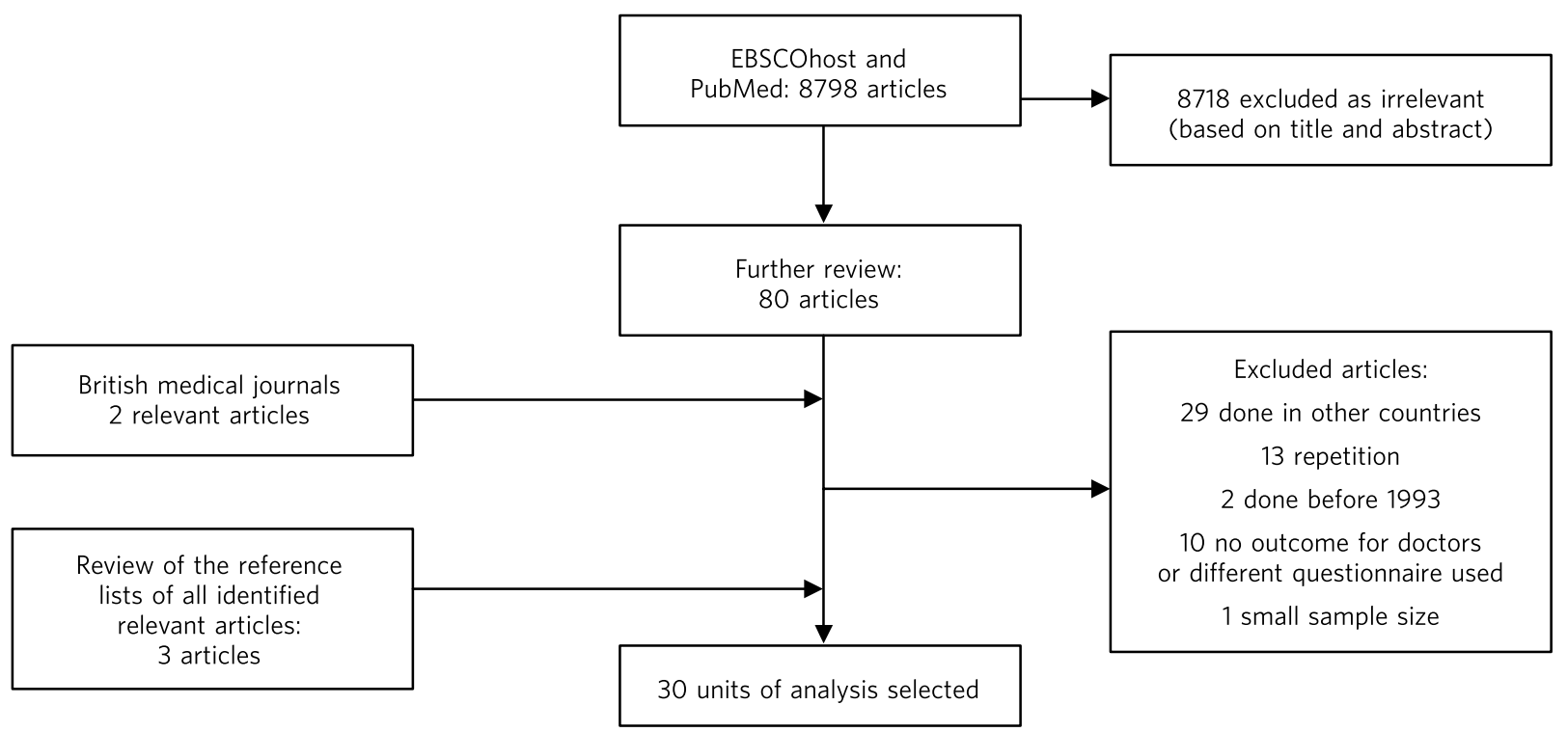

Fig. 1 Flowchart of the study selection process. 


\section{Inclusion criteria}

Certain criteria had to be met before a study was included in the units of analysis:

(a) it had to answer any of the research questions

(b) for the measurement of the prevalence of psychiatric morbidity, the study had to have used any version of the GHQ, and for the prevalence of burnout syndrome only the MBI was considered

(c) population group - only medical doctors in the UK irrespective of which organisation they work in

(d) minimum sample size of 50

(e) published between January 1993 and December 2013

(f) published in the English language.

\section{The questionnaires}

The GHQ is a well-validated and widely used screening tool for the detection of minor psychiatric disorders (psychiatric morbidity) in the general population. ${ }^{19}$ The GHQ-12 is selfadministered and only takes about $5 \mathrm{~min}$ to complete. It enquires about the experience of psychosocial and somatic symptoms in recent weeks. Each of the 12 items is measured on a 4-point Likert scale. Studies validating the GHQ-12 against standardised psychiatric interviews indicate that a cut-off score of 4 or above indicates a high probability that the individual suffers from a clinically significant level of distress ('caseness' or psychiatric morbidity).

The MBI is a 22-item self-report questionnaire, which is well recognised and widely used to measure burnout in relation to occupational stress. ${ }^{20}$ It has three subscales: personal accomplishment (measured by 8 items), depersonalisation (measured by 9 items) and emotional exhaustion (measured by 5 items). Responses are rated for each item according to frequency on a 7-point scale from 'never' to 'every day'. The total score for each subscale is categorised 'low', 'average' or 'high' according to predetermined cut-off scores, based on normative data from a sample of American health professionals. A high degree of burnout is indicated by high scores on the emotional exhaustion and depersonalisation subscales and low scores on the personal accomplishment subscale.

\section{Data extraction}

A simple paper data extraction tool was created in Microsoft Word, and the tables from this have been used to portray the results in the results section. Data were extracted by the author over the months of November and December 2013.

\section{Results}

A total of 30 papers considered relevant and appropriate based on the study inclusion and exclusion criteria were included in this review. Table 1 summarises these papers.

\section{Findings on prevalence}

Seven studies ${ }^{21,22,24,25,27,30,50}$ had quantifiable data on the prevalence of both psychiatric morbidity and burnout (an in-depth analysis of studies reviewed in this paper is included in an online data supplement to this article). Altogether 22 studies reported on prevalence of psychiatric morbidity, and the range was $17-52 \%$ (average $31 \%$ ). GPs and consultants had the highest scores. Fourteen studies had burnout scores, with nine reporting scores as percentages and five as mean scores; one study ${ }^{28}$ had both percentage and mean burnout scores. For emotional exhaustion the scores ranged from 31 to $54.3 \%$ and mean scores ranged from 2.90 to 31.26 ; for depersonalisation the scores ranged from 17.4 to $44.5 \%$ (1.95-15.68) and for low personal accomplishment the range was $6-39.6 \%$ (4.36-34.21). GPs, consultants and pre-registration house officers had the highest levels of burnout in the studies.

McManus et $a l^{46}$ in a UK-wide study carried out in 2009, had the largest sample size at 2845 doctors and reported prevalence of psychiatric morbidity at $19.2 \%$. The other two UK-wide studies with samples of over 1000 cutting across specialties and grades ${ }^{23,43}$ reported psychiatric morbidity prevalence rates of $27.8 \%$ and $21.3 \%$, respectively. Taylor et $a l^{50}$ reviewed 1308 consultants from different specialties and found the prevalence of psychiatric morbidity to be $32 \%$.

One longitudinal study ${ }^{30}$ found no significant increase in the prevalence of psychiatric morbidity over 3 years in a non-specific group of doctors. Another longitudinal study ${ }^{50}$ found a significant increase in psychiatric morbidity and emotional exhaustion among consultants over 8 years.

The only European Union (EU) study looking at the prevalence of burnout in GPs from 12 EU countries ${ }^{39}$ found lower average scores on all burnout scales compared with those of English GPs.

\section{Findings on associated factors}

Job satisfaction was found to be protective against the effect of stress on emotional exhaustion. The number of hours worked, job stress and overload were associated with increased psychiatric morbidity in eight studies. Two studies $^{22,38}$ found that women had significantly higher psychiatric morbidity than men, but three studies ${ }^{27,34,45}$ did not find any association with gender. The personality trait of neuroticism was significantly associated with increase in psychiatric morbidity in three studies, ${ }^{35,43,47}$ while conscientiousness was a protective factor. Psychiatric morbidity was also positively associated with taking work home and with the effect of stress on family life.

Job satisfaction was negatively correlated with burnout in three studies. ${ }^{21,22,25}$ Age was an interesting factor; increased depersonalisation was found in younger doctors in five studies, ${ }^{21,22,27,29,31}$ whereas emotional exhaustion increased with age in two studies. ${ }^{22,41}$ Being single was associated with increased burnout scores, and neuroticism increased burnout significantly in two studies. ${ }^{43,47}$ Increased job stress and workload increased burnout in three studies, with significantly lower emotional exhaustion scores in part-time GPs. 


\begin{tabular}{|c|c|c|c|}
\hline Study & Journal & Running head & Subspecialty/grade \\
\hline Sharma et al (2008) $)^{21}$ & Psycho-Oncology & $\begin{array}{l}\text { Stress and burnout in colorectal and vascular surgical } \\
\text { consultants }\end{array}$ & Surgery/consultants \\
\hline Ramirez et al $(1996)^{22}$ & Lancet & $\begin{array}{l}\text { Mental health of hospital consultants: the effects of } \\
\text { stress and }\end{array}$ & $\begin{array}{l}\text { Surgery, gastro, oncology, } \\
\text { radiology consultants }\end{array}$ \\
\hline Wall et al $(1997)^{23}$ & $\begin{array}{l}\text { British Journal } \\
\text { of Psychiatry }\end{array}$ & $\begin{array}{l}\text { Minor psychiatric disorder in NHS trust staff: } \\
\text { occupational }\end{array}$ & Non-specific \\
\hline Ramirez et al $(1995)^{24}$ & $\begin{array}{l}\text { British Journal } \\
\text { of Cancer }\end{array}$ & $\begin{array}{l}\text { Burnout and psychiatric disorder among cancer } \\
\text { clinicians }\end{array}$ & Oncology/consultants \\
\hline Sharma et al $(2007)^{25}$ & Colorectal Disease & Stress and burnout among colorectal surgeons and & Surgery/consultants \\
\hline Kapur et al $(1999)^{26}$ & Family Practice & $\begin{array}{l}\text { Sources of job satisfaction and psychological } \\
\text { distress in }\end{array}$ & GP, medical house officer \\
\hline Guthrie et al (1999) ${ }^{27}$ & BJPsych Bulletin & Sources of stress, psychological distress and burnout & Psychiatry/non-specific \\
\hline Benbow \& Jolley $(2002)^{28}$ & $\begin{array}{l}\text { International } \\
\text { Journal of Geriatric } \\
\text { Psychiatry }\end{array}$ & Burnout and stress amongst old age psychiatrists & Psychiatry/consultants \\
\hline Orton et al $(2012)^{29}$ & BMJ Open & $\begin{array}{l}\text { Depersonalised doctors: a cross-sectional study of } 564 \\
\text { doctors }\end{array}$ & GP \\
\hline McManus et al $(2002)^{30}$ & Lancet & $\begin{array}{l}\text { The causal links between stress and burnout in a } \\
\text { longitudinal study of UK }\end{array}$ & Non-specific \\
\hline $\begin{array}{l}\text { Kirwan \& Armstrong } \\
(1995)^{31}\end{array}$ & $\begin{array}{l}\text { British Journal } \\
\text { of General Practice }\end{array}$ & $\begin{array}{l}\text { Investigation of burnout in a sample of British general } \\
\text { practitioners }\end{array}$ & GP \\
\hline Kapur et al (1998) 32 & BMJ & $\begin{array}{l}\text { Psychological morbidity and job satisfaction in hospital } \\
\text { consultants }\end{array}$ & Consultants/junior $\mathrm{HO}$ \\
\hline Coomber et al $(2002)^{33}$ & $\begin{array}{l}\text { British Journal } \\
\text { of Anaesthesia }\end{array}$ & Stress in UK intensive care unit doctors & Intensive care/consultants \\
\hline Appleton et al $(1998)^{34}$ & $\begin{array}{l}\text { British Journal } \\
\text { of General Practice }\end{array}$ & $\begin{array}{l}\text { A survey of job satisfaction, sources of stress and } \\
\text { psychological }\end{array}$ & GP \\
\hline $\begin{array}{l}\text { Newbury-Birch \& Kamali } \\
(2001)^{35}\end{array}$ & $\begin{array}{l}\text { Postgraduate Medical } \\
\text { Journal }\end{array}$ & Psychological stress, anxiety, depression, job satisfaction & Junior $\mathrm{HO}$ \\
\hline Cartwright et al $(2002)^{36}$ & $\begin{array}{l}\text { Journal of Clinical } \\
\text { Pathology }\end{array}$ & $\begin{array}{l}\text { Workload and stress in consultant medical microbiolo- } \\
\text { gists }\end{array}$ & $\begin{array}{l}\text { Microbiology/virology } \\
\text { consultants }\end{array}$ \\
\hline Caplan $(1994)^{37}$ & $B M J$ & $\begin{array}{l}\text { Stress, anxiety, and depression in hospital consultants, } \\
\text { general }\end{array}$ & $\begin{array}{l}\text { Consultants } \\
\text { (non-specific), GP }\end{array}$ \\
\hline Burbeck et al $(2002)^{38}$ & $\begin{array}{l}\text { Emergency Medicine } \\
\text { Journal }\end{array}$ & $\begin{array}{l}\text { Occupational stress in consultants in accident and } \\
\text { emergency }\end{array}$ & $\begin{array}{l}\text { Emergency medicine/ } \\
\text { consultants }\end{array}$ \\
\hline Soler et al $(2008)^{39}$ & Family Practice & Burnout in European family doctors: the EGPRN study & GP \\
\hline Bogg et al $(2001)^{40}$ & Medical Education & $\begin{array}{l}\text { Training, job demands and mental health of pre- } \\
\text { registration }\end{array}$ & Pre-registration $\mathrm{HO}$ \\
\hline Upton et al (2012) $)^{41}$ & Surgery & $\begin{array}{l}\text { The experience of burnout across different surgical } \\
\text { specialties }\end{array}$ & Surgery/consultants \\
\hline Sochos \& Bowers $(2012)^{42}$ & $\begin{array}{l}\text { The European Journal } \\
\text { of Psychiatry }\end{array}$ & $\begin{array}{l}\text { Burnout, occupational stressors, and social support in } \\
\text { psychiatric }\end{array}$ & $\begin{array}{l}\text { Psychiatry, medicine/ } \\
\text { senior HO }\end{array}$ \\
\hline McManus et al $(2004)^{43}$ & BMC Medicine & $\begin{array}{l}\text { Stress, burnout and doctors' attitudes to work are } \\
\text { determined }\end{array}$ & Non-specific \\
\hline Paice et al (2002) $)^{44}$ & Medical Education & $\begin{array}{l}\text { Stressful incidents, stress and coping strategies in the } \\
\text { pre-registration }\end{array}$ & Pre-registration $\mathrm{HO}$ \\
\hline Tattersall et al (1999) 45 & Stress Medicine & Stress and coping in hospital doctors & Non-specific \\
\hline McManus et al $(2011)^{46}$ & BMC Medicine & $\begin{array}{l}\text { Vocation and avocation: leisure activities correlate with } \\
\text { professional }\end{array}$ & Non-specific \\
\hline Deary et al $(1996)^{47}$ & $\begin{array}{l}\text { British Journal } \\
\text { of Psychology }\end{array}$ & $\begin{array}{l}\text { Models of job-related stress and personal achievement } \\
\text { among }\end{array}$ & Consultants \\
\hline Thompson et al (2009) ${ }^{48}$ & The Clinical Teacher & $\begin{array}{l}\text { Contemporary experience of stress in UK foundation } \\
\text { doctors }\end{array}$ & Foundation doctors \\
\hline Berman et al $(2007)^{49}$ & Clinical Medicine & $\begin{array}{l}\text { Occupational stress in palliative medicine, medical } \\
\text { oncology }\end{array}$ & $\begin{array}{l}\text { Oncology and palliative } \\
\text { medicine registrars }\end{array}$ \\
\hline Taylor et al $(2005)^{50}$ & Lancet & Changes in mental health of UK hospital consultants & Consultants \\
\hline
\end{tabular}

$\mathrm{GP}$, general practitioner; $\mathrm{HO}$, house officer. 


\section{Findings on the direct relationship between burnout and psychiatric morbidity}

Three studies ${ }^{25,30,46}$ found significant positive correlations between psychiatric morbidity as measured by the GHQ, and burnout syndrome. Using the process of casual modelling, McManus et $a l^{30}$ found that when scores were considered in 1997 and later in 2000, emotional exhaustion increased psychiatric morbidity, and vice versa. Personal accomplishment increased emotional exhaustion directly, and increased psychiatric morbidity directly but also indirectly through increasing emotional exhaustion. When other mental health problems were considered, anxiety and depression were found to increase psychiatric morbidity in three studies, ${ }^{35,37,38}$ and depression increased depersonalisation. ${ }^{41}$

\section{Discussion}

The findings indicate that the prevalence of psychiatric morbidity among UK doctors is quite high, ranging from 17 to $52 \%$. This compares unfavourably with the results from a longitudinal survey of people living in private households within the UK, which found an 18-month period prevalence of common mental disorders to be $21 \% .^{51}$ Only 4 of the 22 studies that reported on psychiatric morbidity found prevalence of less than $21 \%,{ }^{26,30,32,46}$ which is slightly better than $27 \%$ found in a study of palliative care physicians in Western Australia. ${ }^{52}$ An earlier study of junior house officers in the UK found psychiatric morbidity in 50\% of doctors, ${ }^{53}$ but this was in a period when the working pattern of junior doctors was relatively unregulated. More recent studies of junior doctors contained in this review found the prevalence of psychiatric morbidity to be around $19 \%{ }^{26,32}$ Concern over increasing prevalence of common psychiatric illnesses was borne out by the results from the study which found a $5 \%$ increase in morbidity among a cohort of consultants over an 8-year period. ${ }^{50}$

This review also found a high prevalence of burnout among UK doctors measured using the MBI. It lends further support to the growing body of evidence which has found the syndrome of burnout to be prevalent all over the world among health professionals. In a sample of Australian doctors, $24 \%$ suffered burnout; ${ }^{52}$ in a New Zealand sample of medical consultants one in five did; ${ }^{54}$ and in a crosssection of Japanese doctors $19 \%$ were affected. ${ }^{55}$ This review found even higher rates of burnout, with the prevalence of emotional exhaustion ranging from 31 to $54.3 \%$, which would suggest UK doctors are comparatively more prone to burnout. GPs generally had higher scores for burnout, ${ }^{29}$ particularly in the study of European family doctors, ${ }^{39}$ which found that the only countries in which GPs had higher burnout scores than England were Turkey, Italy, Bulgaria and Greece. Emotional exhaustion among a cohort of consultants was shown to have increased over an 8-year period, ${ }^{50}$ with a prevalence of $41 \%$ in 2002 .

This review has been able to pool together different studies which report on factors associated with the development and perpetuation of psychiatric morbidity and burnout. Neuroticism was positively and significantly correlated with psychological distress and burnout in three studies. ${ }^{35,43,47}$ Neuroticism refers to a lack of psychological adjustment and instability leading to a tendency to be stress-prone, anxious, depressed and insecure, and it has been shown to negatively predict extrinsic career success. ${ }^{56}$ McManus et $a l,{ }^{43}$ in a 12-year longitudinal study on a cohort of students who started studying medicine in 1990, found that doctors who are more stressed and emotionally exhausted showed higher levels of neuroticism all through their careers. Neuroticism was also positively associated with perceived high workload. The researchers concluded that neuroticism was not only a correlate but a cause of work-related stress and burnout. Similar findings were noted by Clarke \& Singh $^{57}$ in a study looking at the pessimistic explanatory style of processing information, which is a manifestation of neuroticism. In that study neuroticism was shown to positively predict psychological distress in doctors, and the authors recommended that susceptible doctors should be offered cognitive-behavioural therapy (CBT) to alter their explanatory style.

In an editorial titled 'Why are doctors so unhappy?' Richard Smith stated that the most obvious cause of doctors' unhappiness was that they feel overworked and under-supported. ${ }^{58}$ Job stress, feeling overloaded and the number of hours worked were positively linked to psychiatric 'caseness' and burnout in many of the studies in the present review, and this cut across specialties and grades. A General Medical Council (GMC) survey $^{59}$ of doctors in training found that $22 \%$ felt their working pattern leaves them short of sleep at work, and 59\% said they regularly worked beyond their rostered hours. Increasing job stress without a commensurate increase in job satisfaction was associated with the presence of psychiatric morbidity, and job satisfaction was also positively correlated with illness in six of the reviewed studies. ${ }^{21,22,25,34-36}$ Another significant finding was the correlation between psychiatric disorders and burnout, with the two feeding off each other, leading to worsening outcomes.

The public health importance of these findings cannot be overemphasised. GPs are at the frontline of healthcare delivery in the UK, and around $90 \%$ of all NHS contacts take place in primary care, with nearly 300 million GP consultations a year. ${ }^{60}$ The estimated total number of GP consultations in England rose from 217.3 million in 1995 to 300.4 million in 2008, with a trebling of telephone consultations, and with the highest consultation rates among the growing population of elderly individuals. ${ }^{61}$ Increased live births of over 110000 over the past 10 years, ${ }^{62}$ and an ageing population ${ }^{63}$ have contributed to the pressure felt by services in general. However, in spite of the increased demand on primary care services, the proportion of the NHS budget that is spent on general practice has slumped to record levels, and GPs report that this has compromised the quality of care they can provide. ${ }^{64}$ Under these circumstances, the added expectation from the UK Department of Health that GP surgeries should open for longer hours and should expand patient choice will undoubtedly lead to even more psychological distress and burnout among GPs.

A government-driven emphasis in the NHS on performance management and targets increases job demands and stress among managers, ${ }^{65}$ and increases 
psychiatric morbidity among doctors. The current climate of austerity in the UK, and the expectation that doctors should continue to provide high-quality care to patients within an NHS intending to make $£ 20$ billion worth of savings, ${ }^{66}$ further expose doctors to burnout and stress. Psychiatrists are already having to deal with the expected increase in demand for mental health services stemming from the economic downturn, ${ }^{67}$ and the increase in suicide rates ${ }^{68}$ among the working-age population. Psychiatrists are particularly vulnerable to burnout, and patient suicide is a factor significantly associated with stress and burnout in this group. ${ }^{69}$

Burnout among doctors can affect the entire public health workforce because as a syndrome it is considered 'contagious'. With the push for doctors to take up leadership positions at every level within the NHS a burnt-out doctor can negatively affect the entire healthcare delivery system. Unhealthy coping strategies in response to burnout and stress were identified in this review: these include retiring early, taking work home, taking it out on family, mixing less with friends, and avoidance, all of which work against the development of a healthy work-life balance.

\section{Limitations}

Some key limitations are worth highlighting. First, all the studies were cross-sectional surveys using questionnaires sent to the participants online or by post. Response rates varied, with some as low as $17 \%$, and only in half of the studies was effort made to increase the response rate by sending reminders or repeat questionnaires. Non-response bias could have affected the results. Second, although the MBI was used in all the studies examining burnout, different versions of the MBI were utilised. With the GHQ, some studies used the 28-item version but most used the 12-item version. The cut-off for 'caseness' using the GHQ also differed between studies and ranged between $\geqslant 3$ and $\geqslant 5$. However, these differences may not have significantly affected the overall findings given that a study to validate the two versions of the GHQ found no difference between them, and also established that the different cut-off for 'caseness' did not affect the questionnaire's validity. ${ }^{2}$

The cross-sectional method used for the surveys makes it difficult to draw a firm conclusion on the outcomes from a cause and effect perspective. Also, the number of potential confounders for the presence of burnout and common psychiatric disorders is vast and cannot be controlled for in surveys alone.

The fact that this literature review ends in 2013 may be considered a limitation, but the hope is that this paper will trigger more research in this area, and the author's intention is to update the literature review by 2023 .

\section{Recommendations}

Doctors are ultimately responsible for the quality of care they provide at any time, and they need to be aware of their own vulnerability to burnout and psychiatric illness, and of their impact on patient care. Traditionally, doctors take pride in working a lot of hours, ${ }^{70}$ and are 3 to 4 times less likely to take days off sick compared with other health professionals; ${ }^{71}$ this combination is a recipe for burnout. A whole list of support networks is available on the GMC website, ${ }^{72}$ and doctors should be encouraged to utilise these. However, there is a 'culture of fear' among doctors regarding the GMC, and 96 doctors, a lot of whom had mental health problems, have died by suicide since 2004 while being investigated by the GMC. ${ }^{73}$ A lot more work is therefore needed to make the most vulnerable doctors feel supported.

At an organisational level, approaches designed to reduce the workload of doctors should be prioritised. Changes to doctors' contract of service should reflect an understanding of the impact of work-related factors on the health and well-being of doctors, and any such contract should contain the necessary protections to reduce the experience of psychiatric illness and burnout. The benefits of a healthy workforce on the quality of care provided in the NHS cannot be overstated.

\section{About the author}

Udemezue O. Imo MRCPsych, MSc Public Health, consultant psychiatrist, Royal Oldham Hospital, Cherrywood Clinic, Oldham, UK.

\section{References}

1 NHS Institute for Innovation and Improvement and Academy of Medical Royal Colleges. Medical Leadership Competency Framework: Enhancing Engagement in Medical Leadership. NHS, AMRC, 2010.

2 Goldberg D, Gater R, Sartorius N, Ustun T, Piccinelli M, Gureje O, et al. The validity of two versions of the GHQ in the WHO study of mental illness in general health care. Psychol Med 1997; 27: 191-7.

3 Wu H, Liu L, Wang Y, Gao F, Zhao X, Wang L. Factors associated with burnout among Chinese hospital doctors: a cross-sectional study. BMC Public Health 2013; 13: 786.

4 Maslach C, Schaufeli WB, Leiter MP. Job burnout. Ann Rev Psycho/ 2001; 52: 397-422.

5 Renzi C, Di Pietro C, Tabolli S. Psychiatric morbidity and emotional exhaustion among hospital physicians and nurses: association with perceived job-related factors. Arch Environ Occup Health 2012; 67: 117-23.

6 Nash LM, Daly MG, Kelly PJ, Van Ekert EH, Walter G, Walton M, et al. Factors associated with psychiatric morbidity and hazardous alcohol use in Australian doctors. Med J Aust 2010; 193: 161-6.

7 Firth-Cozens J. Predicting stress in general practitioners: 10 year follow up postal survey. BMJ 1997; 315: 34-5.

8 Shanafelt T. Burnout and self-reported patient care in an internal medicine residency program. Ann Int Med 2002; 136: 358.

9 Shanafelt T, Balch C, Bechamps G, Russell T, Dyrbye L, Satele D, et al. Burnout and medical errors among american surgeons. Ann Surg 2010; 251: $995-1000$.

10 Sutinen R, Kivimäki $M$, Elovainio $M$, Forma P. Associations between stress at work and attitudes towards retirement in hospital physicians. Work Stress 2005; 19: 177-85.

11 Probst H, Griffiths S, Adams R, Hill C. Burnout in therapy radiographers in the UK. Br J Radiol. 2012; 85: e760-5.

12 Roberts S, Jaremin B, Lloyd K. High-risk occupations for suicide. Psychol Med 2012; 43: 1231-40.

13 Sainsbury Centre for Mental Health. Mental Health at Work: Developing the Business Case. Policy Paper 8. SCMH, 2007.

14 National Institute for Health and Care Excellence. Promoting Mental Wellbeing at Work. NICE, 2009. https://www.nice.org.uk/guidance/ ph22/resources/mental-wellbeing-at-work-1996233648325

15 Griffiths S, Thorpe A. Public health in transition: views of the specialist workforce. J R Soc Promot Health 2007; 127: 219-23. 
16 NHS England. GP-led groups ready to take charge of NHS budgets in every community in England. NHS England, 2013, https:// www.england.nhs.uk/2013/03/wave4-auth/

17 Charlton R. GP commissioning in England. Clin Med 2013; 13: 24-6.

18 British Medical Association. Burnout threats prompt staffing level rethink. BMA, 2013 (http://bma.org.uk/news-views-analysis/news/ 2013/june/burnout-threat-prompts-staffing-level-rethink).

19 Goldberg D, Williams P. A User's Guide to the General Health Questionnaire. NFER-Nelson Publishing, 1988.

20 Maslach $C$, Jackson $S$. The measurement of experienced burnout. J Organ Behav 1981; 2: 99-113.

21 Sharma A, Sharp D, Walker L, Monson J. Stress and burnout in colorectal and vascular surgical consultants working in the UK National Health Service. Psychooncol 2008; 17: 570-6.

22 Ramirez A, Graham J, Richards M, Gregory W, Cull A. Mental health of hospital consultants: the effects of stress and satisfaction at work. Lancet 1996; 347: 724-8.

23 Wall T, Bolden R, Borrill C, Carter A, Golya D, Hardy G, et al. Minor psychiatric disorder in NHS trust staff: occupational and gender differences. Br J Psychiatry 1997; 171: 519-23.

24 Ramirez A, Graham J, Richards M, Cull A, Gregory W, Leaning M, et al. Burnout and psychiatric disorder among cancer clinicians. $\mathrm{Br} J$ Cancer 1995; 71: 1263-9.

25 Sharma A, Sharp D, Walker L, Monson J. Stress and burnout among colorectal surgeons and colorectal nurse specialists working in the National Health Service. Colorect Dis 2007; 10: 397-406.

26 Kapur N, Appleton K, Neal RD. Sources of job satisfaction and psychological distress in GPs and medical house officers. Fam Pract 1999; 16: 600-1.

27 Guthrie E, Tattan T, Williams E, Black D, Bacliocotti H. Sources of stress, psychological distress and burnout in psychiatrists: comparison of junior doctors, senior registrars and consultants. Psychiatr Bull 1999; 23: 207-12.

28 Benbow S, Jolley D. Burnout and stress amongst old age psychiatrists. Int J Geriat Psychiatry 2002; 17: 710-14.

29 Orton P, Orton C, Pereira Gray D. Depersonalised doctors: a crosssectional study of 564 doctors, 760 consultations and 1876 patient reports in UK general practice. BMJ Open 2012; 2: e000274.

30 McManus I, Winder B, Gordon D. The causal links between stress and burnout in a longitudinal study of UK doctors. Lancet 2002; 359: 2089-90.

31 Kirwan M, Armstrong D. Investigation of burnout in a sample of British general practitioners. Br J Gen Pract 1995; 45: 259-60.

32 Kapur N, Borrill C, Stride C. Psychological morbidity and job satisfaction in hospital consultants and junior house officers: multicentre, cross sectional survey. BMJ 1998; 317: 511-12.

33 Coomber S, Todd C, Park G, Baxter P, Firth-Cozens J, Shore S. Stress in UK intensive care unit. Br J Anaesth 2002; 89: 873-81.

34 Appleton K, House A, Dowell A. A survey of job satisfaction, sources of stress and psychological symptoms among general practitioners in Leeds. Br J Gen Pract 1998; 48: 1059-63.

35 Newbury-Birch D, Kamali F. Psychological stress, anxiety, depression, job satisfaction, and personality characteristics in preregistration house officers. Postgrad Med J 2001; 77: 109-11.

36 Cartwright K, Lewis D, Roberts C, Bint A, Nichols T, Warburton F. Workload and stress in consultant medical microbiologists and virologists: a questionnaire survey. J Clin Path 2002; 55: 200-5.

37 Caplan RP. Stress, anxiety, and depression in hospital consultants, general practitioners, and senior health service managers. BMJ 1994; 309: 1261-3.

38 Burbeck R, Coomber S, Robinson SM, Todd C. Occupational stress in consultants in accident and emergency medicine: a national survey of levels of stress at work. Emerg Med J 2002; 19: 234-8.

39 Soler J, Yaman H, Esteva M, Dobbs F, Asenova R, Katic M, et al. Burnout in European family doctors: the EGPRN study. Fam Pract 2008 ; 25: $245-65$
40 Bogg J, Gibbs T, Bundred P. Training, job demands and mental health of pre-registration house officers. Med Educ 2001; 35: 590-5.

41 Upton D, Mason V, Doran B, Solowiej K, Shiralkar U, Shiralkar S. The experience of burnout across different surgical specialties in the United Kingdom: a cross-sectional survey. Surgery 2012; 151: 493-501.

42 Sochos A, Bowers A. Burnout, occupational stressors, and social support in psychiatric and medical trainees. Eur J Psychiat 2012; 26 196-206.

43 McManus I, Keeling A, Paice E. Stress, burnout and doctors' attitudes to work are determined by personality and learning style: a twelve year longitudinal study of UK medical graduates. BMC Med 2004; 2: 29.

44 Paice $E$, Rutter $H$, Wetherell $M$, Winder $B$, McManus I. Stressful incidents, stress and coping strategies in the pre-registration house officer year. Med Educ 2002; 36: 56-65.

45 Tattersall A, Bennett $P$, Pugh S. Stress and coping in hospital doctors. Stress Med 1999; 15: 109-13.

46 McManus I, Jonvik H, Richards P, Paice E. Vocation and avocation leisure activities correlate with professional engagement, but not burnout, in a cross-sectional survey of UK doctors. BMC Medicine 2011; 9: 100

47 Deary I, Blenkin H, Agius R, Endler N, Zealley H, Wood R. Models of jobrelated stress and personal achievement among consultant doctors. $\mathrm{Br}$ Psychol 1996; 87: 3-29.

48 Thompson N, Corbett S, Larsen L, Welfare M, Chiappa C. Contemporary experience of stress in UK Foundation level doctors. Clin Teach 2009; 6 83-6.

49 Berman R, Campbell M, Makin W, Todd C. Occupational stress in palliative medicine, medical oncology and clinical oncology specialist registrars. Clin Med 2007; 7: 235-42.

50 Taylor C, Graham J, Potts H, Richards M, Ramirez A. Changes in menta health of UK hospital consultants since the mid-1990s. Lancet 2005; 366: $742-4$.

51 Office for National Statistics. Better or Worse: A Longitudinal Study of the Mental Health of Adults Living in Private Households in Great Britain. ONS, 2013.

52 Dunwoodie DA Auret K. Psychological morbidity and burnout in palliative care doctors in Western Australia. Int Med J 2007; 37: 693-8.

53 Firth-Cozens J. Emotional distress in junior house officers. BMJ 1987; 295: 533-5.

54 Surgenor LJ, Spearing RL, Horn J, Beautrais AL, Mulder RT, Chen P. Burnout in hospital-based medical consultants in the New Zealand public health system. NZ Med J 2009; 122: 11-8.

55 Tokuda Y, Hayano K, Ozaki M, Bito S, Yanai H, Koizumi S. The interrelationships between working conditions, job satisfaction, burnout and mental health among hospital physicians in Japan: a path analysis. Ind Health 2009; 47: 166-72.

56 Judge T, Higgins C, Thoresen C, Barrick M. The big five personality traits, general mental ability, and career success across the life span. Personnel Psychol 1999; 52: 621-52.

57 Clarke D, Singh R. The influence of pessimistic explanatory style on the relation between stressful life events and hospital doctors psychological distress. Soc Behav Pers 2005; 33: 259-72.

58 Smith R. Why are doctors so unhappy? BMJ 2001; 322: 1073-4.

59 General Medical Council. National Training Survey 2013: Key Findings. GMC, 2013

60 Department of Health. Departmental Report: The Health and Personal Social Services Programmes. Department of Health, 2008.

61 NHS Information Centre and Department of Health. Trends in Consultation Rates in General Practice 1995 to 2008: Analysis of the QResearch database. NHSIC, Department of Health, 2009.

62 Office for National Statistics. Birth summary tables, England and Wales, 2012. ONS, 2012 (http://www.ons.gov.uk/ons/publications/re-referencetables.html?edition $=$ tcm\%3A77-314475)

63 Office for National Statistics. What Does the 2011 Census Tell Us About Older People. ONS, 2013 
64 Royal College of General Practitioners. Patient Care Compromised as Funding for General Practice Slumps Across the UK. RCGP, 2013.

65 Miller K. Gendered nature of managerialism? Case of the National Health Service. IJPSM 2009; 22: 104-13.

66 Department of Health. Equity and Excellence: Liberating the NHS. Department of Health, 2010.

67 Royal College of Psychiatrists. Mental Health and the Economic Downturn: National Priorities and NHS Solutions (Occasional Paper OP70). RCPsych, 2009.

68 Office for National Statistics. Suicides in the United Kingdom, 2011. ONS, 2011.
69 Fothergill A, Edwards D, Burnard P. Stress, burnout, coping and stress management in psychiatrists: findings from a systematic review. Int $J$ Soc Psychiatry 2004; 50: 54-65.

70 General Medical Council. The impact of the implementation of the European Working Time Directive (EWTD). GMC, 2011.

71 Health and Social Care Information Centre. Sickness absence rates in the NHS-August 2013. HSCIC, 2013.

72 General Medical Council. Doctors Health Concerns. GMC, 2014.

73 Dyer C. GMC and vulnerable doctors: too blunt an instrument? BMJ 2013; 347: f6230.

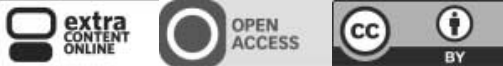

